\title{
Economic crisis and rising gaps North-South: evidence from the Italian regions
}

\author{
Raffaele Lagravinese
}

Department of Economics, Uniroma Tre University and Rossi-Doria Center, Roma Tre

University, 77 S.D.Amico, 00145 Rome, Italy, raffaele.lagravinese@uniroma3.it

Received on August 22, 2014; accepted on January 28, 2015

This study investigates the economic crises that occurred in Italy between 1970 and 2011 , referring in particular to the employment level and the different effects on the Italian regions. Empirical results suggest that regions with a larger share of manufacturing or a higher number of temporary workers suffered to a greater extent than others during recessions. In contrast, regions with higher percentages of public employees and service industries were better able to 'resist' the negative phases of the economy. Moreover, the recent crisis has exacerbated the strong imbalances between the North and South making rebalancing policies necessary to place the country on a sustainable growth path.

Keywords: regional economic growth, recessionary shock

JEL Classifications: E320, H7, L1, R1

\section{Introduction}

The financial crisis that originated in the USA rapidly spread to Europe, with especially severe effects on countries characterised by weak banking sectors and large public budget deficits. European countries have responded to these financial difficulties with different interventions: for example, Germany and France have significantly increased public expenditures, including regional policy instruments designed to stimulate domestic demand and cope with economic difficulties. Other countries, such as Italy and the UK, instead shifted resources from the regions to the central government with the goal of developing anti-crisis policy capable of returning their economies to a growth path (Davies, 2011). In addition to the differences between countries, the economic crisis has fuelled and accentuated significant differences within individual states. This issue has become much more pronounced in countries with marked historical differences, such as the UK, Spain and Italy. This has attracted the interest of several scholars from different disciplines, especially regional economists and economic geographers who are investigating the policies necessary to recover from the economic crisis. More specifically, several studies have focused on the concept of 'resilience', a term borrowed from engineering sciences (Holling, 1973; Pimm, 1984; Walker et al., 2009), ecology (McGlade et al., 2006), psychology (Bonanno, 2004; Bonanno et al., 2006) and only recently employed in economics terms. In 
recent years, the term 'regional resilience' has become popular because of its association with regional adaptation and so has strong connections with evolutionary economics and evolutionary economic geography (see Martin and Sunley, 2014). One obvious question is why the concept has become so popular at this historical moment. The processes it encompasses (rebound, adaptation and recovery) certainly are not new in any fundamental sense. The attention to resilience may be, however, a response to a generalised contemporary sense of uncertainty and insecurity and a search for formulas for adaptation and survival. In this respect, the fashionable use of the concept may originate both from an increased sense of risk (economic and political as well as environmental) and from the perception that processes associated with globalisation have made places and regions more permeable to the effects of what were once thought to be external processes. The social and economic paradigm seems to be permanently mutated, and therefore also the way to face the future will necessarily change. To look to the future, it is often necessary to start from past experience, and this work analyses the major economic crisis that hit the Italian regions (1970-1972, 1992-1995 and 2008-2010) and the subsequent periods of growth (1973-1991 and 1996-2007), trying to identify the 'resilient regions'. The majority of studies on regional resilience have been designed to investigate the effects of the economic downturn in the UK: Martin (2012) and Fingleton et al. (2012) analysed the effects of the total employment in the last three UK recessions and devoted particular attention to the strong heterogeneity observed across different areas of the country. Lee (2014) investigated the impact of the 2008-2009 recession on unemployment in the 60 largest cities in Great Britain. However, beyond those on the UK regions, few studies to date have considered other European states. Yet, significant differences are also present in other countries, such as Spain, Germany and particularly, Italy.
The first work that analysed the resilience of the Italian regions was the paper by Cellini and Torrisi (2014) that investigated the effects of major economic crises on per capita income over a very long period of time (1890-2009). More recently, others scientific papers (Di Caro, 2015, 2014; Modica and Reggiani, 2014) with more sophisticated econometric techniques have studied the effects of crisis on employment and value added in the Italian regions. Compared with these works, this paper investigates the role of specialisation and industrial structure in the ability of regions in Italy to withstand shocks. Having investigated the stylised facts of regional recession and recovery using the resilience measure adopted by Martin (2012), this study uses a decomposition technique known as multi-factor partitioning (MFP) to disentangle the role played by the sectorial specialisation during the period of recession. Finally, this work emphasises the effect of the recent crisis on the gap between the North and South, which has always characterised the Italian economy, but that currently appears to have grown to a greater extent than in the past.

\section{The effects of the economic crisis on the Italian regions}

The economic crises that have occurred in Italy in the last 40 years have had different effects on the Italian regions. Following the approach of Martin (2012) and Fingleton et al. (2012), the focus of analysis is employment rather than income. The employment experienced during an economic recession tends to return to pre-crisis levels with a much longer lag than output, which can lead to significant imbalances in the labour market, causing substantial inequality and social tension. Data was collected on regional employment from the Cambridge Econometrics database for the period between 1970 and 2011. Unlike the two works quoted, annual values were used rather than quarterly ones due to data availability. 
However, this does not imply biased data analysis. As shown in Figure 1, it is possible to identify three major economic shocks that resulted in a significant reduction in the employment rate during the 1970-2011 period. Specifically, the first shock is identifiable in the 1970-1973 period. This sudden decline in the employment rate was primarily due to the oil crisis and strong inflationary pressures that affected Italy in that period.

The second shock is identifiable in the 19921995 period. The crisis was created by substantial internal problems in the preceding years, such as hyper devaluation of the Lira, scandals and political corruption ('Mani Pulite' operation-'clean hands'), which led Italy into a phase of strong political and economic instability. After the crisis years (1992-1995), the Italian economy returned to growth, but much more slowly than in the past. For this reason, Italy has been defined 'the sick man of Europe' (King, 1992; Mammone and Veltri, 2010).

The last recent recession was 2008-2010, which primarily resulted from a financial crisis, caused by the credit crunch in the USA that rapidly expanded to Europe and more significantly affected vulnerable countries with political instability and severe sovereign debt problems such as Greece and Italy. Furthermore, after a slight recovery in 2011, the economy plunged into a deep structural crisis, with strong recessionary effects in 20122013 (ISTAT, 2014). This later period is not included in the analysis.

\section{Regional resilience: resistance and recovery}

In recent years, many econometric methodologies have been developed to identify a resilient regions (see Martin and Sunley, 2014). In this paper, I have adopted the simplest measure of resilience, used by Martin (2012) in conjunction with those of 'resistance' and 'recovery'. Martin (2012) highlights how the effect of an economic downturn on the regional economy is composed of two phases: the first phase is that of the shock itself, whereas the second phase is to recover from the shock. By determining the resistance index and the recovery index it will be possible to identify the so-called 'resilient regions'.

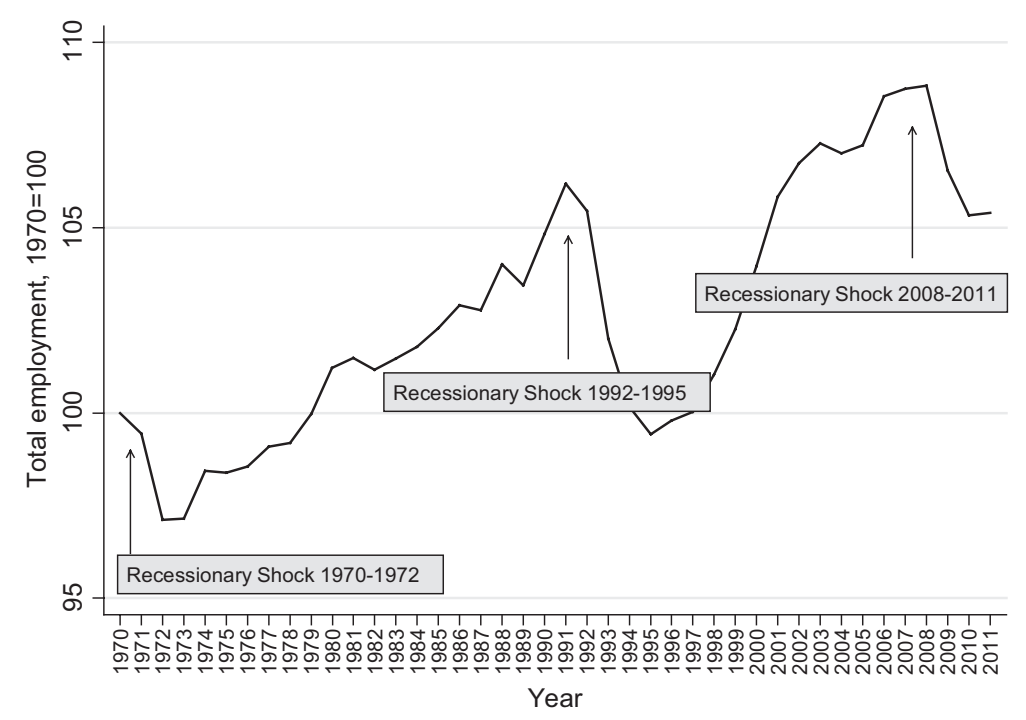

Figure 1. Total employment in Italy (1970-2011). 
Specifically, the resistance index $\left(\beta_{\text {res }}\right)$ is calculated as follows:

$$
\beta_{\text {res }}=\left[\left(\Delta \mathrm{E}_{\mathrm{r}} / \mathrm{E}_{\mathrm{r}}\right)-\left(\Delta \mathrm{E}_{\mathrm{N}} / \mathrm{E}_{\mathrm{N}}\right)\right] /\left|\Delta \mathrm{E}_{\mathrm{N}} / \mathrm{E}_{\mathrm{N}}\right| .
$$

Where $\left(\Delta E_{r} / E_{r}\right)$ and $\left(\Delta E_{N} / E_{N}\right)$ are the percentage changes in employment at the regional and national levels, respectively.

A positive value of $\beta_{\text {res }}$ indicates that the region exhibits greater 'resistance' to an adverse shock compared with the rest of the country. A negative value of $\beta_{\text {res }}$ indicates that the region is less resistant than the nation; $\beta_{\text {res }}$ equals zero represents no difference to the national effect.

$$
\beta_{\text {rec }}=\left(\Delta \mathrm{E}_{\mathrm{r}} / \mathrm{E}_{\mathrm{r}}\right) /\left(\Delta \mathrm{E}_{\mathrm{N}} / \mathrm{E}_{\mathrm{N}}\right) .
$$

A value of $\beta_{\text {rec }}$ greater than one indicates a stronger (relative to the nation) performance after the recession period. A value of $\beta_{\text {rec }}$ lower than one indicates a weaker (relative to the nation) performance. $\beta_{\text {rec }}$ equals zero represents no difference to the national effect.

Figure 2 plots the relationship across the Italian regions between the resistance index (average of three recession periods) and the recoverability index (average of two postrecession periods). Furthermore, by partitioning the relationship into quadrants, defined by the national resistance index (1.00) and national recoverability index, the five northern regions of the Lazio, Trentino A.A., Valle d'Aosta, Veneto and Lombardy stand out as having been both the most resistant to the recession and as having experienced the fastest post-recession employment growth.

\section{Industry and regional effects during the recession period}

Certain economic sectors are known to be more subject to cyclical economic fluctuations than others and as such suffer the most from economic downturns (Conroy, 1975, Dissart, 2003; Ormerod, 2010; Siegel et al., 1995). The manufacturing and construction industries typically appear to suffer to a greater extent than the services sector during an economic crisis. The latter is more flexible and can absorb and renew itself more rapidly than the former. Furthermore, the presence

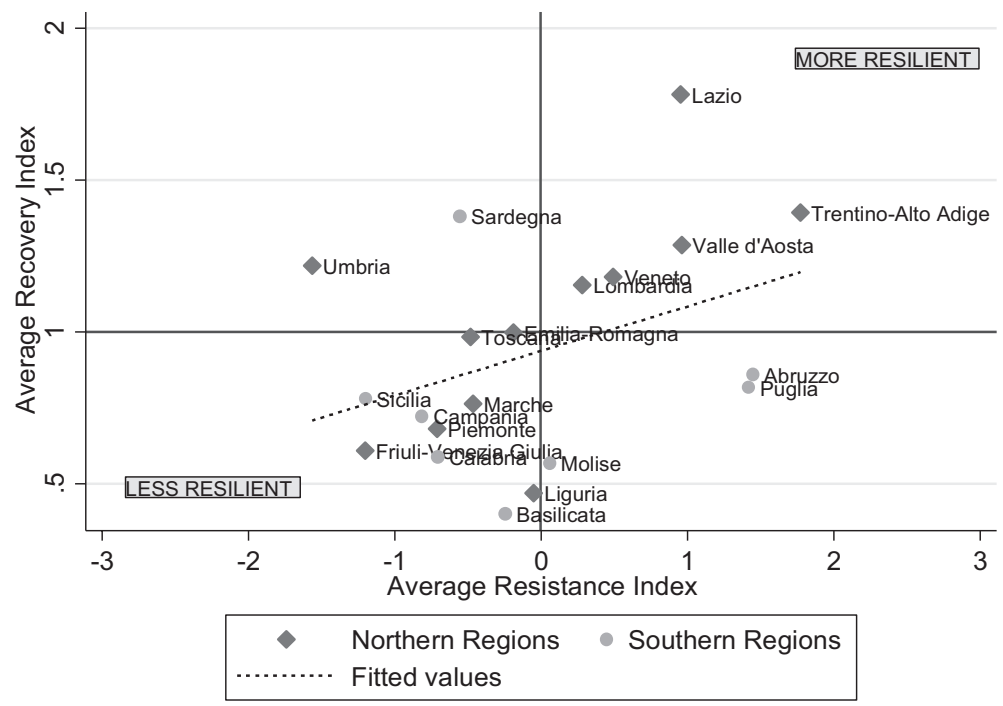

Figure 2. Resistance versus recovery index.

Note: Average resistance index computed on three recession periods 1970-1972, 1992-1995 and 2008-2010. Average recovery index for two post-recession period 1973-1991 and 1996-2007. 


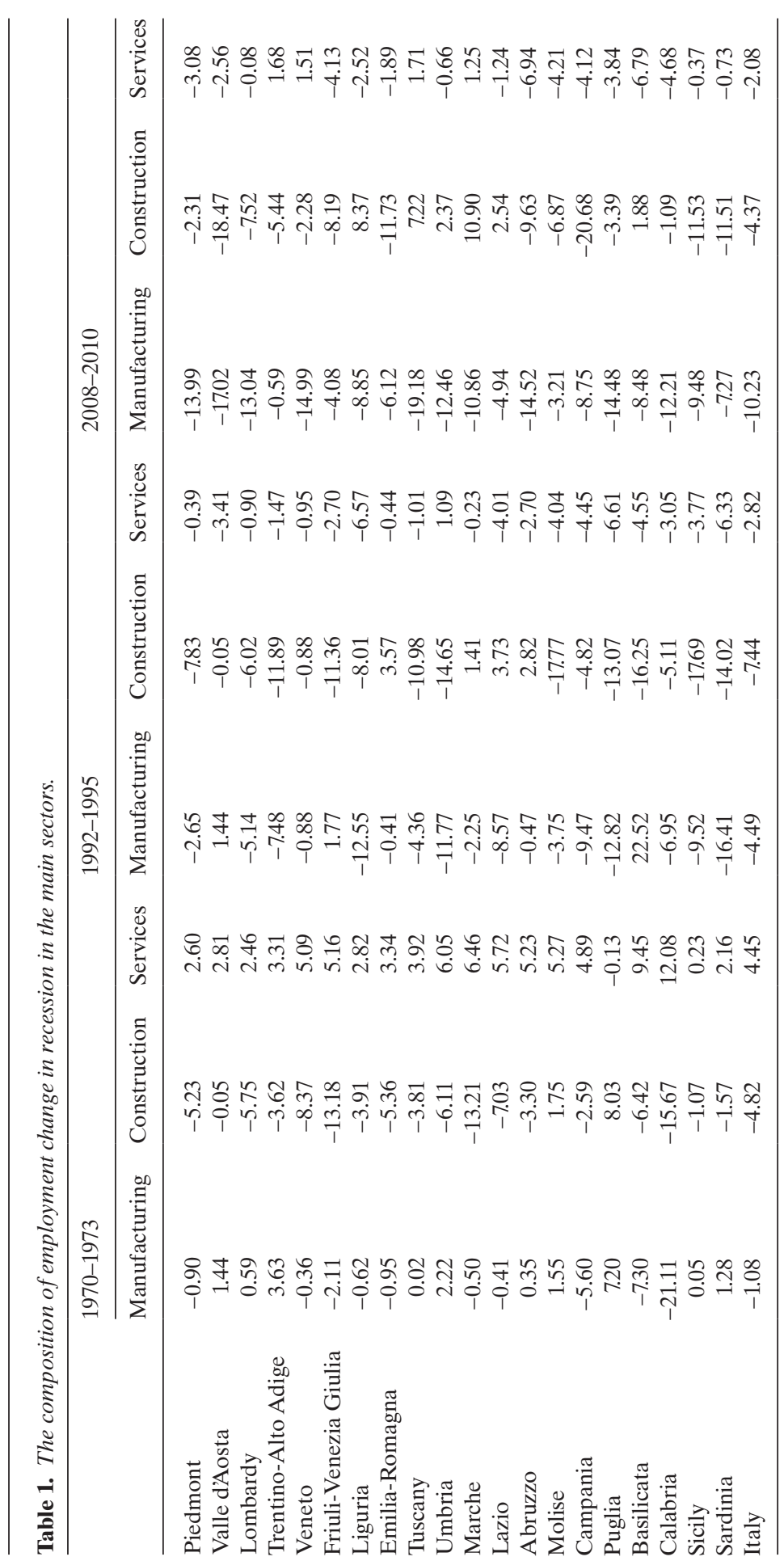


Table 2. Percentage of civil servants and temporary employees in Italian regions (2008-2010).

\begin{tabular}{lll}
\hline & $\begin{array}{l}\text { Civil } \\
\text { servants, \% }\end{array}$ & $\begin{array}{l}\text { Temporary } \\
\text { employees, \% }\end{array}$ \\
\hline Piedmont & 5.01 & 11.57 \\
Valle d'Aosta & 9.31 & 12.07 \\
Liguria & 6.1 & 11.88 \\
Lombardy & 4.17 & 9.09 \\
Trentino-Alto Adige & 7.19 & 15.14 \\
Veneto & 4.63 & 10.39 \\
Friuli-Venezia Giulia & 6.76 & 12.08 \\
Emilia-Romagna & 5.19 & 12.95 \\
Tuscany & 5.62 & 14.02 \\
Umbria & 5.51 & 14.43 \\
Marche & 5.27 & 13.35 \\
Lazio & 6.9 & 10.59 \\
Abruzzo & 5.37 & 12.85 \\
Molise & 6.22 & 12.46 \\
Campania & 5.21 & 13.50 \\
Puglia & 5.23 & 18.98 \\
Basilicata & 5.54 & 15.65 \\
Calabria & 5.92 & 20.77 \\
Sicily & 5.49 & 18.96 \\
Sardinia & 6.29 & 16.94 \\
Italy & 5.36 & 12.76 \\
\hline & &
\end{tabular}

of a significant number of public employees enhances resilience to economic shocks, managing nearly completely to absorb the effects of the recession. The geographical distribution of these activities across regions might then be expected to be relevant in explaining spatial differences in resistance to recessionary shocks (Martin, 2012). However, much will depend on the nature of the crisis.

Table 1 examines these issues during the recent crises. In the last recession, the manufacturing sector has decreased by $10.40 \%$ points. The highest decline compared with the previous two crises (4.49 and 1.08, respectively). The construction sector has fallen by $4.43 \%$ and the service sector of 2.82. Furthermore, the crisis of 2008-2010 has had dramatic effects on all Italian regions. In the previous crises, the northern regions were better able to withstand recessionary effects.

Another element to consider in the analysis of employment is the type of employer: public or private. Table 2 presents the percentage of public employees by region and the percentage of employees with fixed-term employment contracts. Regions such as Trentino Alto Adige, Valle d'Aosta and Lazio have larger numbers of workers employed in the public sector and were also less affected by the recession than other regions. An interesting result can also be observed from Table 2 for temporary workers. Since the early 2000s, the Italian labour market has become much more flexible, especially for new employees, with far fewer safeguards than in the past and hence is much more exposed to the effect of economic crises. Unsurprisingly, therefore, southern regions, such as Puglia, Campania, Calabria, Sicily and Sardinia, where there are more workers with fixed-term contracts, are also the regions that have suffered from the effects of the crisis to a greater extent than others.

\section{MFP analysis}

The ability of a region to withstand and recover from an economic crisis can be determined by its industrial specialisation and the nature of the crisis that hit the region's economy. In order to connect the concept of 'resilience' to the concept of 'regional competitiveness', the MFP approach was adopted to disentangle the effects of industrial structure, regional characteristics and interaction effects, in relative regional performance, during the periods of two recent recessions (for an extensive explanation of this procedure, see Gardiner et al., 2013; Ray et al., 2012).

The MFP procedures uses standardised growth rates to remove the confounding of compositional effects found in conventional shift share analysis. The standardised regional employment growth rate over the recession period $t$ to $k$ is defined as follows:

$$
\hat{g}_{i}{ }^{t+k}=\sum_{j} g_{i j}^{t+k}\left(Y_{j N}^{t} / Y_{N}^{t}\right)
$$


where $i$ refers to region and $j$ refers to industry. $g_{i j}^{t+k}$ is the crude growth rate of industry $j$ in the region $i$. It is possible to write the standardised industry growth rate for each industry as follows:

$$
\hat{g}_{j N}^{t+k}=\sum_{j} g_{i j}^{t+k}\left(Y_{i}^{t} / Y_{N}^{t}\right) .
$$

The standardised national rate can thus be calculated using the standardised industry or region rates:

$$
\hat{g}_{N}^{t+k}=\sum_{j} g_{i j}^{t+k}\left(Y_{j N}^{t} / Y_{N}^{t}\right)=\sum_{j} g_{i j}^{t+k}\left(Y_{i}^{t} / Y_{N}^{t}\right) .
$$

The weights used to calculate standardised industry (region) rates are the same for every industry, namely the total in each region (industry) as a proportion of the total national figure. Once the crude and standardised growth rates have been calculated, partitioning the effects into the component parts is relatively straightforward, as shown below:

$$
\begin{aligned}
& Y_{i}^{t+k}\left(g_{i}^{t+k}-g N t+k\right)=\sum_{j} Y_{i j}^{t+k}\left(\begin{array}{c}
{ }^{t+k} \\
\hat{g}_{i N}-\hat{g}_{N}{ }^{t+k}
\end{array}\right)+ \\
& \sum_{j} Y_{i j}^{t+k}\left(\hat{g}^{t+k}-\hat{g}_{N}^{t+k}\right)+ \\
& \sum_{j} Y_{i j}^{t+k}\left(g^{t+k}-\hat{g}_{j N}^{t+k}-\hat{g}^{t+k}+g_{N}^{t+k}\right)+
\end{aligned}
$$

(4)

$$
\sum_{j} Y_{i j}^{t+k}\left(\hat{g}_{N}^{t+k}-g_{N}^{t+k}\right)
$$

Where,

(1) is the difference between regional employment growth and the national effect or component in a downturn;

(2) is the industry mix effect, which is the fall on regional employment in a recession assuming that each industry in the region declines at the same rate as that same sector nationally;
(3) is the 'regional shift', which reflects the presence of regional-specific factors, that influence how a region's firm responds in employment during a recession period;

(4) is the net effect of all of the interactions between these components in a given region; is the residual allocation effect.

The analysis used in this procedure involved a sectoral disaggregation (agricultural, manufacturing, construction, distribution, transport and communications services, financial business services, non-market services), which was the most detailed possible to provide consistent data available for the period 1970-2011. Figure 3 gives the percentage of industry mix, regional shift and industry-region interaction to each region's differential response (relative to national response) during the two recession periods.

The regional effect is strongly negative in both recessions, in almost all southern regions that have lower relative resistance to and slower recoverability from downturn, such as Puglia, Campania, Molise and Calabria. Conversely, in the northern regions, the regional effect is positive in those regions with higher relative resistance and faster recoverability, such as Trento and Bolzano (autonomous provinces) Lazio, Veneto and Lombardia. The effect of industrial structure is adverse, more specifically in the last recession, in Veneto, Marche, Abruzzo, Lombardia and Veneto, showing a deep crisis. The northern industrial system has always been based on small- and medium-sized manufacturing enterprises, organised in industrial districts at the local level and specialised in one or more phases of the production process. This organisational system has long been a factor in competitiveness. However today, with competition from countries such as China and India (where the labour cost is much lower), the industrial system is in crisis. Only firms that export are able to compete on international markets. Investment in human capital and in the services with high technological specialisation is, therefore, crucial 


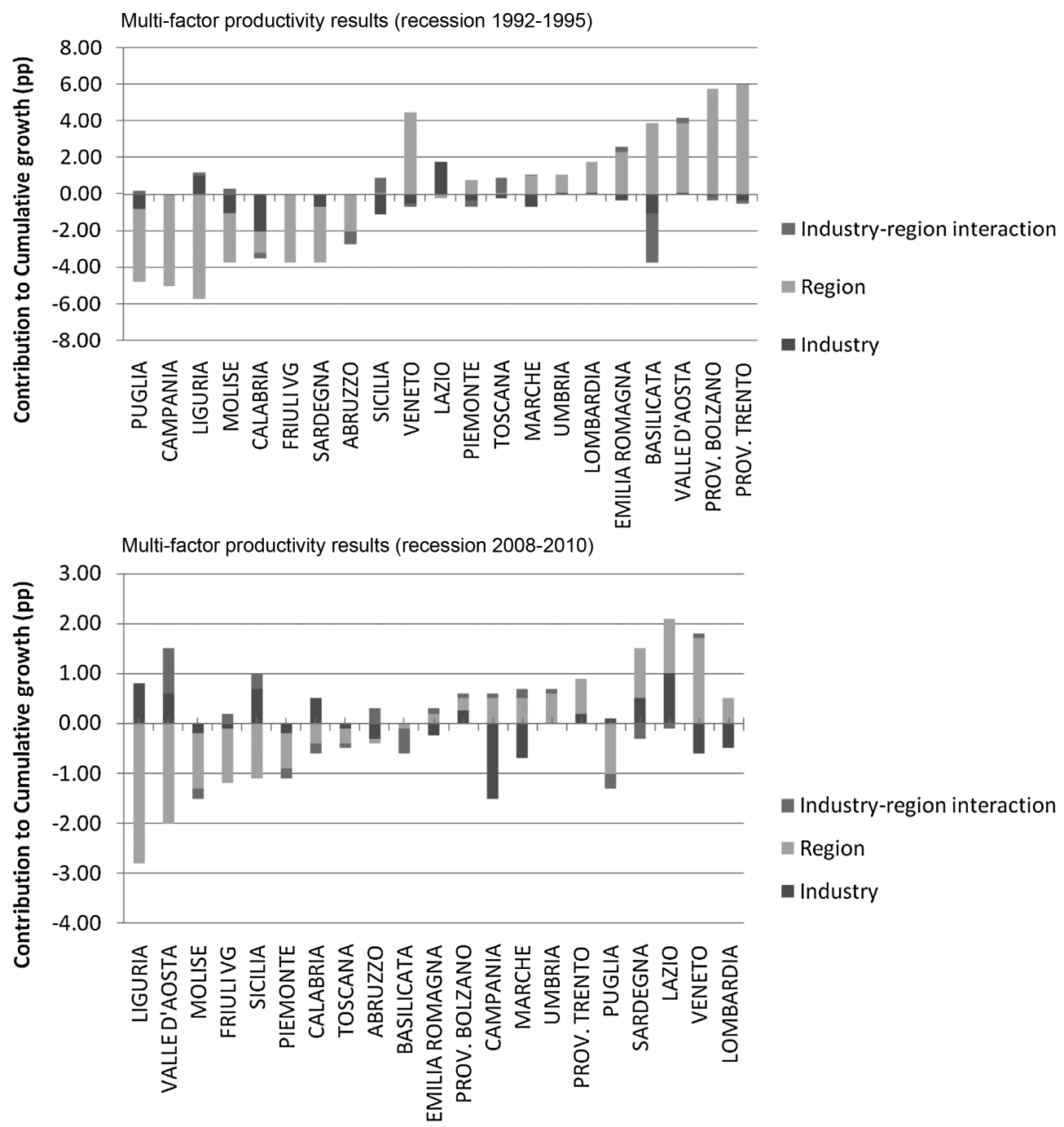

Figure 3. The contribution of industry mix and regional competitiveness effects during the recession period.

for the entire production system. Furthermore, the entry into the Euro area (2002) has prohibited currency devaluation policy to improve the competitiveness of Italian products in foreign markets. This sheds light on some of the most important issues related to structural weaknesses of the Italian economic system, such as the lack of institutional reform and lack of investment in infrastructure and innovation. Widespread corruption at all levels of society and the high levels of political instability have also worsened the economic situation. Among the northern regions, Liguria, Piedmont and Friuli V.G. experienced a deep industrial crisis. The industrial system of the Lazio region instead (based on services and public administration) seems to have withstood the crisis better than others with a positive industry-effect. Not surprisingly, therefore, the Lazio region is also the more resilient region. 
During the period 1970-2011, a marked shift of employment out of production industries into services occurred in all of the major regions of the country. Table 3 shows the local quotient (LQ) and the percentage of employment in industry and services sectors in the last years of the recession periods. Lazio is the region most highly specialised in the service sector. This has allowed it to better mitigate the crisis. Especially since 2000, with the digital age and globalisation, the service sector has become crucial to maintaining competitiveness in relation to other areas of the globe. The other richer regions of the country (for example, Lombardy, Veneto, Emilia and Tuscany) have maintained a mix of industry and the services sector. The case of the Piedmont region is emblematic. It is the seat of the most important Italian automotive company (FIAT). In the 80s, during the boom years of the automotive industry, this region was among the richest in Italy, whereas in the last decade, the crisis in the automotive industry has coincided with the decline of the region.
This is similar to what happened in Detroit (seat of Chrysler and GM, in the crisis during the 90s and 2000) in the USA (Crandall, 2009; Ryan and Campo, 2013). Very often, the regional specialisation in a specific industrial sector is an advantage during the periods of economic growth, but at the same time, it can become a disadvantage in times of crisis.

\section{The recent crisis and the growing gap between North and South}

The large socioeconomic divide in Italy has been widely analysed in previous studies (Gonzales, 2011; Guerrieri and Iammarino, 2007; Rossi, 2004; Viesti, 2003), which have stressed the significant differences between the different areas of the country. As shown in Figure 4, it is clear that the gap between the two areas of the country has become more pronounced during the recession period. Indeed, one of the most striking features to emerge from this analysis

Table 3. Regional dependence on manufacturing and services industries (percentage of total employment and location quotient).

\begin{tabular}{|c|c|c|c|c|c|c|}
\hline & \multicolumn{2}{|l|}{ 1973, \% (LQ) } & \multicolumn{2}{|l|}{ 1996, \% (LQ) } & \multicolumn{2}{|l|}{ 2010, \% (LQ) } \\
\hline & Manufacturing & Services & Manufacturing & Services & Manufacturing & Services \\
\hline Piedmont & $39.29(1.37)$ & $38.86(1.30)$ & $29.79(1.11)$ & $57.59(0.85)$ & $21.44(0.92)$ & $67.06(0.98)$ \\
\hline Valle d'Aosta & $18.81(0.66)$ & $51.29(0.51)$ & $11.79(0.53)$ & $70.34(1.12)$ & $12.33(1.12)$ & $72.57(1.06)$ \\
\hline Liguria & $43.50(1.52)$ & $42.75(1.38)$ & $31.56(1.33)$ & $58.02(0.94)$ & $29.90(0.93)$ & $65.85(0.96)$ \\
\hline Lombardy & $19.58(0.68)$ & $54.09(0.72)$ & $16.54(0.87)$ & $66.22(1.18)$ & $22.15(1.06)$ & $69.11(1.01)$ \\
\hline Trentino A.A. & $36.16(1.26)$ & $39.59(1.40)$ & $32.14(1.43)$ & $54.59(0.87)$ & $34.19(0.87)$ & $60.50(0.88)$ \\
\hline Veneto & $28.81(1.01)$ & $49.68(1.12)$ & $25.78(1.21)$ & 62.32 (1.09) & $23.63(0.99)$ & $67.40(0.98)$ \\
\hline Friuli V.G. & $21.30(0.74)$ & $62.32(0.57)$ & $13.1(0.61)$ & 76.25 (1.37) & $11.01(1.22)$ & 76.35 (1.11) \\
\hline Emilia-Romagna & 31.24 (1.09) & $43.48(1.22)$ & $28.01(1.33)$ & $57.44(0.95)$ & $29.42(0.92)$ & $63.69(0.93)$ \\
\hline Tuscany & $33.36(1.17)$ & $45.51(1.15)$ & $26.25(1.01)$ & $62.86(1.00)$ & $22.55(1.00)$ & $69.34(1.01)$ \\
\hline Umbria & $29.81(1.04)$ & $35.73(0.95)$ & $21.86(1.03)$ & $61.51(0.78)$ & $23.19(0.98)$ & $68.39(1.00)$ \\
\hline Marche & $30.73(1.07)$ & $37.19(1.36)$ & $31.25(1.56)$ & $55.25(0.81)$ & $32.32(0.88)$ & $59.11(0.86)$ \\
\hline Lazio & $15.12(0.53)$ & $63.04(0.48)$ & $11.02(0.45)$ & 78.05 (1.38) & $12.58(1.24)$ & 81.04 (1.18) \\
\hline Abruzzo & $24.19(0.85)$ & $33.12(1.00)$ & $22.89(1.16)$ & $57.87(0.73)$ & $23.94(0.92)$ & $61.98(0.91)$ \\
\hline Molise & $13.74(0.48)$ & $29.57(0.76)$ & 17.33 (1.03) & $56.63(0.65)$ & $19.10(0.90)$ & $61.10(0.89)$ \\
\hline Campania & $18.98(0.66)$ & $45.69(0.67)$ & $15.41(0.61)$ & $67.88(1.00)$ & 11.51 (1.08) & 74.14 (1.08) \\
\hline Puglia & $19.62(0.69)$ & $49.64(0.75)$ & $17.16(0.76)$ & $61.86(1.09)$ & $15.03(0.99)$ & $65.96(0.96)$ \\
\hline Basilicata & $13.83(0.48)$ & $30.41(0.72)$ & $16.46(0.82)$ & $56.89(0.67)$ & $14.16(0.91)$ & $62.50(0.91)$ \\
\hline Calabria & $11.10(0.39)$ & $41.99(0.39)$ & $8.85(0.45)$ & $65.03(0.92)$ & 8.87 (1.04) & $67.73(0.99)$ \\
\hline Sicily & $14.24(0.50)$ & $50.79(0.46)$ & $10.48(0.51)$ & $70.50(1.11)$ & 9.97 (1.12) & 74.38 (1.09) \\
\hline Sardinia & $15.07(0.53)$ & $51.16(0.51)$ & $11.61(0.57)$ & $68.37(1.12)$ & 13.22 (1.09) & 74.61 (1.09) \\
\hline
\end{tabular}




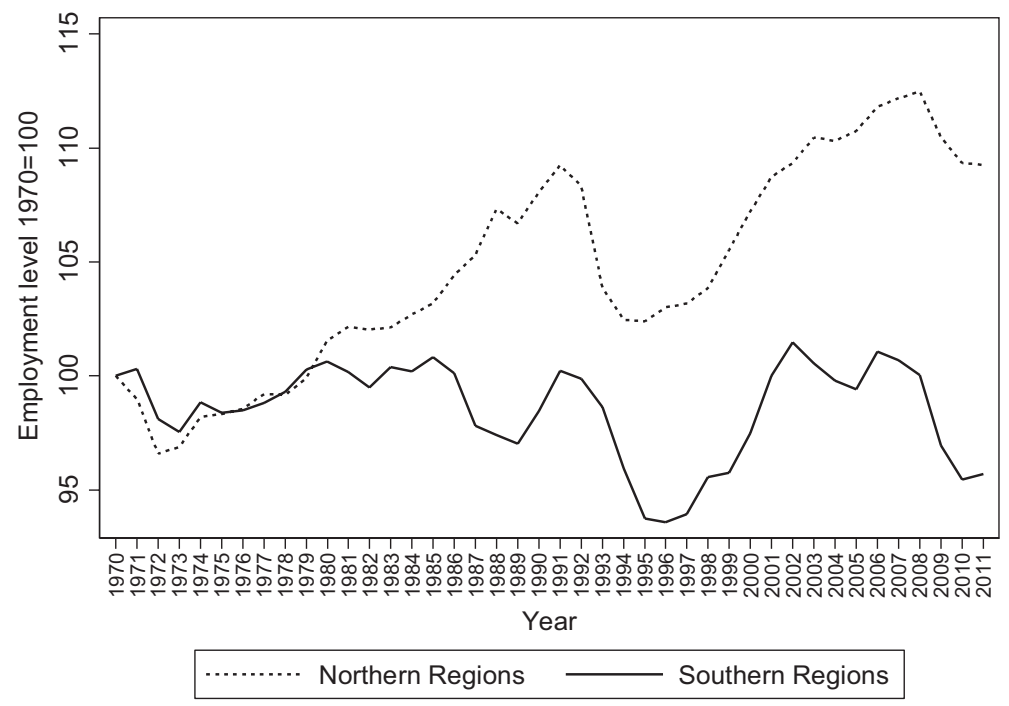

Figure 4. Total employment in North-South (1970-2011).

Note: Northern regions: Piemonte, Valle d’Aosta, Lombardia, Liguria, Trentino A.A., Friuli V. G., Veneto, Emilia Romagna, Toscana, Marche, Umbria, Lazio. Southern regions: Abruzzo, Molise, Campania, Puglia, Basilicata, Calabria, Sicilia, Sardegna.

is the marked contrast in resilience and longrun growth between the North and South of the country. This is particularly evident after the recession of 1995, where the northern regions recover rapidly and appear to be much more resilient than regions in the South. In the southern regions, after a slight recovery in the early 2000s, the economy plunged into a deep structural crisis, with strong recessionary effects in 2008-2010.

The process of convergence has been very slow and the gap has remained almost unchanged over past years. Each region has independently developed its own development policies. However, in the medium term, these development strategies have not generated the expected results. This large gap between the two areas of the country has produced for a long time (and today, substantially increased after the recent crisis) strong labour migratory flows toward the North or abroad (Biagi et al., 2011). This problem is associated with the worrying phenomenon of 'brain drain', which every year sees thousands of young people with a high education migrate to the northern regions or to foreign countries, weakening the human capital of the southern regions. Viesti (2005) and Fratesi and Percoco (2014) found that these migrations are reducing the quality of human capital in the southern regions, adversely affecting the regional growth. These large differences have also repercussions in terms of infrastructure, services and therefore income inequalities. Placing 'the Questione meridionale' at the top of the government's agenda then would not only benefit the southern regions, but it could also ensure growth throughout the country.

\section{Conclusion}

This paper has focused on the idea of resilience in relation to regional specialisation. During the crisis period, certain economic sectors suffer more than others. The latest crisis has shown a sharp decline in the manufacturing and construction sectors with significant repercussions in the northern and southern regions. Indeed, the manufacturing and construction industries typically appear to suffer to a greater extent than the services sector during an economic 
crisis. The service sector is more flexible and able to renew itself more quickly during a recession. Our findings suggest that the presence of a significant number of public employees enhances resilience to economic shocks, managing nearly completely to absorb the effects of the recession. In this respect, the industrial system of the Lazio region (the region of Rome) seems to have withstood the crisis better than others. In the last 40 years, all industry sectors have changed significantly, however, what emerges from our analysis is that regional disparities continue to persist over time. The recent economic crisis has returned the issue of unbalanced growth. From this analysis emerged a marked contrast in resilience and long-run growth between the North and South. This has become more evident after the recession of 1995. After this time, the paths of these two areas have started to diverge significantly: In the northern regions, employment continued to grow, especially in the service and financial sectors; whereas in the southern regions, employment remained stable, marking a slow decline of the Italian economy.

Future work will be used to refine the statistical methods to analyse the relationship between the industrial specialisation and the ability of a region to recover from a recession. Each region may react differently to periods of crisis. This may depend on several factors and the industrial specialisation seems to be a crucial point. Further studies on this field are needed to help policy makers implement policies and reforms that can mitigate the recessionary effects and provide the basis for sustained and stable regional economic growth.

\section{Acknowledgments}

The author wishes to thank Ben Gardiner, Achille Puggioni, Gilda Mazzarelli, Nicola Coniglio and Maurizio Lozzi for the useful comments and suggestions. We also would like to thank two anonymous referees for their insightful comments. A preliminary version of this paper was presented at the conference AISRE (Associazione italiana di economia regionale) Padova, 11-13 September 2014. The work for this paper forms part of a larger project on 'Resilience, Recovery and Growth: An Analysis of European Regions' funded by Rossi-Doria Center and Economics Department of Roma Tre University (791/2014).

\section{References}

Biagi, B., Faggian, A. and McCann, P. (2011) Long and short distance migration in Italy: the role of economic, social and environmental characteristics, Spatial Economic Analysis, 6: 111-131.

Bonanno, G. A. (2004) Loss, trauma, and human resilience: have we underestimated the human capacity to thrive after extremely aversive events? The American Psychologist, 59: 20-28.

Bonanno, G. A., Galea, S., Bucciarelli, A. and Vlahov, D. (2006) Psychological resilience after disaster New York city in the aftermath of the September 11th terrorist attack, Psychological Science, 17: 181-186.

Cellini, R. and Torrisi, G. (2014) Regional resilience in Italy: a very long-run analysis, Regional Studies, 48:1179-1196.

Conroy,M.(1975) Regional Economic Diversification. New York: Praeger.

Crandall, R. W. (2009) The decline in US manufacturing before and during the current crisis, L'industria, 30: 679-702.

Davies, S. (2011) Regional resilience in the 20082010 downturn: comparative evidence from European countries, Cambridge Journal of Regions, Economy and Society, 4: 369-382.

Di Caro, P. (2015) Recessions, recoveries and regional resilience: evidence on Italy, Cambridge Journal of Regions, Economy and Society, 8: 273-291.

Di Caro, P. (2014) Testing and explaining economic resilience with an application to Italian regions. SSRN Working Paper. Available online at: http:// ssrn.com/abstract=2469221. [Accessed 1 June 2014]

Dissart, J. C. (2003) Regional economic diversity and regional economic stability: research results and agenda, International Regional Science Review, 26: 193-204.

Fingleton, B., Garretsen, H. and Martin, R. (2012) Recessionary shocks and regional employment: evidence on the resilience of UK regions, Journal of Regional Science, 52: 109-133.

Fratesi, U. and Percoco, M. (2014) Selective migration, regional growth and convergence: evidence from Italy, Regional Studies, 48.10: 1650-1668. 
Gardiner, B., Martin, R., Sunley, P. and Tyler P. (2013) Spatially unbalanced growth in the British economy, Journal of Economic Geography, 13: 889-928.

Gonzales, S. (2011) The North/South divide in Italy and England: discursive construction of regional inequality, European Urban and Regional Studies, 18: $62-76$.

Guerrieri, P. and Iammarino, S. (2007) Dynamics of export specialization in the regions of the Italian Mezzogiorno: persistence and change, Regional Studies, 41: 933-948.

Holling, C. S. (1973) Resilience and stability of ecological systems, Annual Review of Ecology and Systematics, 4: 1-23.

ISTAT. (2014) Occupati e Disoccupati. Available online at: http://www.istat.it/it/archivio/137142 [Accessed 31 October 2014].

King, R. (1992) Italy: from sick man to rich man of Europe, Geography, 77: 153-169.

Lee, N. (2014) Grim down South? The determinants of unemployment increases in British cities in the 2008-2009 recession, Regional Studies, 48: 1761-1778.

Mammone, A. and Veltri, G. A. (eds) (2010) Italy Today: The Sick Man of Europe. Oxford: Routledge.

Martin, R. (2012) Regional economic resilience, hysteresis and recessionary shocks, Journal of Economic Geography, 12: 1-32.

Martin, R. and Sunley, P. (2014) On the notion of regional economic resilience: conceptualization and explanation, Journal of Economic Geography. doi: $10.1093 / \mathrm{jeg} / \mathrm{lbu} 015$.

McGlade, J., Murray R., Baldwin, J., Ridgway, K. and Winder, B. (2006) Industrial resilience and decline: a co-evolutionary framework. In E. Garnsey and
J. McGlade (eds) Complexity and Co-Evolution: Continuity, Glos, Elgar.

Modica, M. and Reggiani, A. (2014) Spatial economic resilience: overview and perspectives, Networks and Spatial Economics. doi: 10.1007/ s11067-014-9261-7.

Ormerod, P. (2010) Resilience after local economic shocks, Applied Economics Letters, 17: 503-507.

Pimm, S. L. (1984) The complexity and stability of economic systems, Nature, 307: 321-326.

Ray, D. M., Lamarche, R. H. and Beaudin, M. (2012) Economic growth and restructuring in Canada's heartland and hinterland: from shift-share to multifactor partitioning, The Canadian Geographer/ Le Géographecanadien, 56: 296-317.

Rossi, U. (2004) New regionalism contested: some remarks in light of the case of the Mezzogiorno of Italy, International Journal of Urban and Regional Research, 28: 466-477.

Ryan, B. D. and Campo, D. (2013) Autopia's end the decline and fall of detroit's automotive manufacturing landscape, Journal of Planning History, 12: 95-132.

Siegel, P. B., Alwang, J. and Johnson, T. G. (1995) A structural decomposition of regional economic stability: a conceptual framework, Journal of Regional Science, 35: 457-470.

Viesti, G. (2003) Abolire il Mezzogiorno. Bari-Roma: Laterza.

Viesti, G. (2005) Nuove migrazioni. Il "trasferimento" di forza lavoro giovane e qualificata dal Sud al Nord. Bologna: Il Mulino.

Walker, B. H., Abel, N., Anderies, J. M. and Ryan, P. (2009) Resilience, adaptability, and transformability in the Goulburn-Broken catchment, Australia, Ecology and Society, 14: 12-36. 